\title{
Plasma Free Thyroxine (FT4) Concentrations during Hemodialysis in Patients with Chronic Renal Failure: Effects of Plasma Non-Esterified Fatty Acids on FT4 Measurement
}

\author{
MitSUSHIGE NISHIKAWA, YOSHIFUMI OGAWA, NORIO YOSHIKAWA, MASAYOSHI YOSHIMURA, \\ NAGAOKI TOYODA, AKIRA SHOUZU, AND MitSUO INADA
}

Second Department of Internal Medicine, Kansai Medical University, Osaka 570, Japan

\begin{abstract}
Plasma free T4 (FT4) concentrations could be increased during hemodialysis in patients with chronic renal failure (CRF) because an increase in non-esterified fatty acids (NEFA) could interfere with the binding of T4 to thyroxine-binding globulin. To evaluate the effect of hemodialysis on the FT4 concentration in patients with CRF, we measured the FT4 in 39 patients with CRF by four assay methods including equilibrium dialysis, the ${ }^{125} \mathrm{I}-\mathrm{T} 4$ analog method and enzyme immunoassay. The addition of the fatty acid sodium oleate to normal pooled sera led to a marked increase in FT4 as measured by equilibrium dialysis (Model FT4). A moderate increase in the serum FT4 concentration also was observed with an IMX enzyme immunoassay kit, whereas the Coat-A-Count analog method demonstrated no interference by sodium oleate. The mean serum FT4 prior to hemodialysis measured by equilibrium dialysis did not differ significantly from that in the normal control, although those measured by analog methods (Coat-A-Count and Amerlex) and IMX were subnormal. The FT4 by IMX were albumin-dependent, and the values decreased as the samples were serially diluted, but Model FT4 was not affected by the albumin level or the serial dilution. FT4 by Model FT4 showed a marked increase beginning $10 \mathrm{~min}$ after the start of dialysis, and it correlated well with the plasma concentration of NEFA and the NEFA/albumin molar ratio. The other three assay methods, including one which is not affected by NEFA, did not show a change in FT4 at $10 \mathrm{~min}$, but a significant increase of 11 to $17 \%$ was observed by the end of dialysis. The TSH concentration decreased significantly during hemodialysis. These data suggest that (1) the low serum FT4 in hemodialysis patients measured by some immunoassay methods may be an underestimation due to the low albumin level; (2) FT4 actually increases during hemodialysis due to the actual increase in NEFA, although the marked increase in FT4 during hemodialysis as measured by equilibrium dialysis is an overestimation due to the in vitro generation of NEFA; and (3) one should beware of abberations in thyroid hormone parameters during hemodialysis and potential complications.
\end{abstract}

Key words: Free T4, TSH, Hemodialysis, Fatty acid, Heparin

(Endocrine Journal 43: 487-493, 1996)

NON-ESTERIFIED fatty acids (NEFA) have been reported to interfere with the binding of thyroxine

Received: November 27, 1995

Accepted: May 7, 1996

Correspondence to: Mitsushige NISHIKAWA, Second Department of Internal Medicine, Kansai Medical University, 10-15 Fumizonocho, Moriguchi, Osaka 570, Japan
(T4) to thyroxine-binding globulin (TBG) [1-3] and may be a cause of the increased serum free $\mathrm{T} 4$ (FT4) concentrations in patients with nonthyroidal illnesses (NTI) [4-6]. Nevertheless, measurement of FT4 by equilibrium dialysis has been reported to be affected by NEFA generated during incubation in vitro [7], especially when the molar ratio of NEFA to albumin exceeded 5. Patients with a low serum albumin concentration, and those with hy- 
pertriglyceridemia, might develop an increased FT4 concentration during heparin therapy, because hypertriglyceridemia would increase the NEFA concentration because plasma triglycerides serve as the major substrate for heparin-released lipases [8]. Patients undergoing hemodialysis with use of heparin may therefore have both of these risk factors, because hypoalbuminemia and hypertriglyceridemia are frequent in this population [9].

It was reported previously [10] that the FT4 concentration increased and the TSH decreased during $\mathrm{HD}$, as assessed by using equilibrium dialysis assay for FT4 and radioimmunoassay for TSH, but FT4 might have been influenced in the equilibrium dialysis assay by NEFA in vitro, as mentioned above, and certain radioimmunoassays also are known to be affected by NEFA [11, 12]. Several immunoassay methods for FT4 have been developed $[11,13,14]$, including one which is minimally affected by NEFA, and the TSH concentration can be measured by more sensitive and specific assay methods. In the present study, we have evaluated the FT4 and TSH concentrations in patients with chronic renal failure, including the changes induced by hemodialysis, and have discussed the effects of NEFA on FT4 measurements.

\section{Subjects and Methods}

\section{FT4 measurements before hemodialysis}

The serum FT4 concentration was measured prior to regularly scheduled hemodialysis, in 27 patients with chronic renal failure, by the equilibrium dialysis method with the Model FT4 (Nihon Mediphysics, Nishinomiya, Japan) and IMX FT4 kits (Dainabot, Tokyo, Japan). The underlying disease causing chronic renal failure was chronic glomerulonephritis in 16 patients and diabetic nephropathy in the remaining patients. The Model FT4 serum analysis kit involves overnight dialysis of $0.2 \mathrm{ml}$ undiluted serum against the 2.4 $\mathrm{m} l$ buffer at $37^{\circ} \mathrm{C}$, followed by radioimmunoassay for T4 in the dialysate. In preliminary experiments, as the dialysable fraction in serum is diluted 13 times before FT4 measurement, we measured FT4 in two serum samples after serial dilutions with the buffer to examine the effect of dilution on FT4 measurement. The FT4 level (T4 concentration in the dialysate) of one sample (original concentration: $1.82 \mathrm{ng} / \mathrm{d} l$ ) after the 32-time dilution was 1.62 $\mathrm{ng} / \mathrm{d} l$, and that of the other $(4.50 \mathrm{ng} / \mathrm{d} l)$ was 4.52 $\mathrm{ng} / \mathrm{d} l$ with no significant fluctuation due to the serial dilutions. The FT4 level was therefore found not to be changed up to the 32-time (final; 416time) dilution of the sample. The IMX kit requires $0.1 \mathrm{ml}$ of serum and employs a 2-step enzyme immunoassay with anti-T4 antibody immobilized on microparticles and alkaline phosphatase-labeled T3. The 1:1 dilution of a serum sample with phosphate buffered saline resulted in about a $15 \%$ decrease in FT4 (IMX), and further serial 1:1 dilutions resulted in further decreases of 26 and $28 \%$, respectively.

\section{Changes during hemodialysis}

We studied the changes in total protein, albumin, NEFA, T4, FT4 and TSH during hemodialysis in nine of the 27 patients. Approximately $2000 \mathrm{U}$ of heparin was infused at the start of hemodialysis in a bolus followed by the continuous infusion of $500 \mathrm{U} / \mathrm{h}$ during hemodialysis. Serum or plasma samples were obtained just before and at $10 \mathrm{~min}$ and $4 \mathrm{~h}$ after the start of the dialysis, and FT4 was measured by the above methods.

In another series of 12 patients with chronic renal failure, samples were obtained before and at 1 , 2 and $4 \mathrm{~h}$ after the start of dialysis. In this series, FT4 concentrations were measured with Amerlex FT4 (Kodak Clinical Diagnostics, England) and the Coat-A-Count FT4 (Japan DPC Corporation, Tokyo, Japan) assay kits. The Amerlex FT4 kit employs a ${ }^{125} \mathrm{I}$ labeled analog of T4; and a $0.1 \mathrm{ml}$ sample serum, $0.5 \mathrm{ml} \mathrm{T} 4$ analogue and $0.5 \mathrm{ml}$ diluted antibody were used. Coat-A-Count is a solid phase radioimmunoassay which also uses undiluted serum and a ${ }^{125} \mathrm{I}$ labeled T4 analog [15].

The TSH concentration was measured by a radiometric assay, Riagnost hTSH (Hoechst, Japan), the detection limit being $0.2 \mu \mathrm{U} / \mathrm{mL}$. T4 and T3 were measured with solid-phase radioimmunoassay kits (Eiken, Japan). Cortisol was measured by fluorescence polarization immunoassay (Dainabot, Japan), and NEFA, by means of an autoanalyser with enzymatic determination.

\section{In vitro experiments}

Up to $8 \mathrm{mmol} / \mathrm{L}$ of sodium oleate was added as 
a physiologic fatty acid (sodium oleate of 11 to 88 $\mathrm{mmol} / \mathrm{L}$ in water was added while mixing thoroughly with two normal serum samples in one-tenth the original serum volume) to normal pooled sera, and FT4 and TSH concentrations were measured by the various methods described.

\section{Sample management and statistics}

Serum and plasma samples were centrifuged immediately after collection and stored at $-20^{\circ} \mathrm{C}$ until used. The FT4 assays were done in a single assay for each series within the 1 week after sampling. To evaluate the effect of in vitro incubation on NEFA generation, some serum samples were collected before hemodialysis and plasma samples were collected during hemodialysis, and divided into two portions. One was incubated overnight at $37^{\circ} \mathrm{C}$ and the other was stored at $-20^{\circ} \mathrm{C}$, and the NEFA concentration was then measured.

Data were expressed as the mean \pm SEM. The difference between the means of the two groups was analysed by Student's paired $t$ test. The correlation coefficient was calculated by the least square method.

\section{Results}

\section{Serum concentrations prior to hemodialysis}

FT4 concentrations measured by equilibrium dialysis (Model FT4) in 27 patients with CRF prior to hemodialysis averaged $1.47 \pm 0.09 \mathrm{ng} / \mathrm{dl}$, which did not differ significantly from that of normal controls $(1.44 \pm 0.03 \mathrm{ng} / \mathrm{d} l, \mathrm{n}=99)$. But, when measured by IMX, the FT4 values were lower than the normal range $(0.99-1.71 \mathrm{ng} / \mathrm{d} l)$ in six of 27 patients, the mean value $(1.05 \pm 0.06)$ being significantly lower than that in normal controls. The mean serum total protein concentration prior to dialysis in nine patients was $6.3 \pm 0.1 \mathrm{~g} / \mathrm{dL}$ and the mean albumin concentration $(3.2 \pm 0.1 \mathrm{~g} / \mathrm{dL})$ was lower than that in normal controls (Table 1, upper part). There was no significant relation between Model FT4 levels and albumin, but IMX FT4 was decreased in patients with low albumin concentrations. Total $\mathrm{T} 4$ ranged from 4.1 to $10 \mu \mathrm{g} / \mathrm{d} l$ prior to hemodialysis, with two cases being below the normal range. T3 was subnormal $(<84 \mathrm{ng} / \mathrm{d} l)$ in seven patients, and the mean value $(75 \pm 10 \mathrm{ng} / \mathrm{d} l)$ was lower than that in normal controls.

The TSH concentration varied widely from 0.2 to $8.0 \mu \mathrm{U} / \mathrm{mL}(2.65 \pm 0.77 \mu \mathrm{U} / \mathrm{mL})$ before hemodialysis. No patient had a serum NEFA concentration higher than the upper limit of normal. The serum triglyceride concentration was supranormal in five of seven patients. The molar ratio of NEFA/albumin in this group ranged from 0.08-0.32, the average being $0.18 \pm 0.03$ (Table 1 , upper part).

\section{Changes during hemodialysis}

Total serum protein and albumin increased by about 0.4 and $0.2 \mathrm{~g} / \mathrm{dL}$, respectively, by the end of dialysis, showing a hemoconcentration of about $6 \%$. The total T4 increased by about $5 \%$ by the end of dialysis which is comparable to the increase in the TBG level due to hemoconcentration. The NEFA concentrations had increased noticeably $10 \mathrm{~min}$ after the start of dialysis and remained high during hemodialysis (Table 1, upper part).

The FT4 concentration as measured by IMX increased significantly by approximately $11 \%$ from 1.06 to $1.18 \mathrm{ng} / \mathrm{d} l$ by the end of hemodialysis. No significant change was observed during the first 10 min. But, the FT4 concentration obtained by equilibrium dialysis (Model FT4) had increased noticeably from $1.55 \pm 0.10$ to $2.24 \pm 0.22$ (by about $45 \%)$ at $10 \mathrm{~min}$. At the end of hemodialysis, the FT4 concentration had decreased to $1.90 \mathrm{ng} / \mathrm{d} l$, which was still much higher than before hemodialysis.

Significant positive correlations were observed between the increase in the NEFA concentration or NEFA/albumin ratio and the FT4 concentration as measured by the Model-FT4 system at $10 \mathrm{~min}$ $(\mathrm{r}=0.916, P<0.01$, Fig. 1 for NEFA and FT4, and $\mathrm{r}=0.86, P<0.01$, for NEFA/albumin and FT4).

The TSH concentration tended to have decreased $(0.05<P<0.1) 10 \mathrm{~min}$ after the start of dialysis, and had also decreased slightly at the end of dialysis in five of nine patients.

To further confirm these changes, similar studies were performed in another series of 12 patients receiving hemodialysis. FT4 was measured with Coat-A-Count FT4 and Amerlex FT4 kits employing T4-derivatives.

When measured with these kits, FT4 concentrations were lower than those of normal controls, 
Table 1. Changes in serum and plasma concentrations during hemodialysis

\begin{tabular}{|c|c|c|c|c|c|c|c|c|c|}
\hline & & $\begin{array}{c}\mathrm{TP} \\
\mathrm{g} / \mathrm{d} l\end{array}$ & $\begin{array}{l}\text { Alb } \\
\mathrm{g} / \mathrm{d} l\end{array}$ & $\begin{array}{c}\text { FFA } \\
\mu \mathrm{mol} / l\end{array}$ & $\begin{array}{c}\mathrm{T} 4 \\
\mu \mathrm{g} / \mathrm{d} l\end{array}$ & $\begin{array}{c}\mathrm{FT} 4-1^{* 1} \\
\mathrm{ng} / \mathrm{d} l\end{array}$ & $\begin{array}{c}\mathrm{FT} 4-2^{* 2} \\
\mathrm{ng} / \mathrm{d} l\end{array}$ & $\begin{array}{c}\mathrm{TSH} \\
\mu \mathrm{U} / \mathrm{m} l\end{array}$ & $\begin{array}{c}\text { FFA/ } \\
\text { albumin }\end{array}$ \\
\hline \multicolumn{10}{|c|}{ Study $1(n=9)$} \\
\hline \multirow[t]{2}{*}{ Before } & M & 6.3 & 3.2 & 85 & 6.2 & 1.06 & 1.55 & 2.65 & 0.18 \\
\hline & SEM & 0.1 & 0.1 & 11 & 0.6 & 0.07 & 0.10 & 0.77 & 0.03 \\
\hline \multirow[t]{2}{*}{$10 \mathrm{~min}$} & M & 6.3 & 3.2 & 940 & 6.2 & 1.07 & $2.24^{* 3}$ & 2.44 & $1.92^{* 3}$ \\
\hline & SEM & 0.1 & 0.1 & 280 & 0.6 & 0.07 & 0.22 & 0.67 & 0.50 \\
\hline \multirow[t]{2}{*}{$240 \mathrm{~min}$} & M & $6.7^{* 3}$ & $3.4^{* 3}$ & $860^{* 4}$ & $6.5^{* 3}$ & $1.18^{* 3}$ & $1.90^{* 3}$ & 2.51 & $1.71^{* 4}$ \\
\hline & SEM & 0.2 & 0.2 & 160 & 0.6 & 0.07 & 0.16 & 0.77 & 0.28 \\
\hline \multicolumn{10}{|c|}{ Study $2(n=12)$} \\
\hline \multirow[t]{2}{*}{ Before } & M & 6.5 & 3.0 & 111 & 4.8 & 0.63 & 0.75 & 2.97 & 0.23 \\
\hline & SEM & 0.1 & 0.4 & 25 & 0.4 & 0.03 & 0.05 & 0.71 & 0.05 \\
\hline \multirow[t]{2}{*}{$60 \mathrm{~min}$} & M & 6.6 & $\mathrm{nd}^{* 5}$ & $935^{* 4}$ & 4.6 & 0.60 & 0.74 & $2.79 * 3$ & nd \\
\hline & SEM & 0.1 & nd & 258 & 0.3 & 0.03 & 0.04 & 0.73 & nd \\
\hline \multirow[t]{2}{*}{$120 \mathrm{~min}$} & $M$ & 6.9 & nd & $994^{* 4}$ & $5.5^{* 1}$ & 0.62 & $0.82^{* 4}$ & $2.60^{* 4}$ & nd \\
\hline & SEM & 0.2 & nd & 191 & 0.5 & 0.04 & 0.06 & 0.68 & nd \\
\hline \multirow[t]{2}{*}{$240 \mathrm{~min}$} & $M$ & $7.1^{* 4}$ & $3.2^{* 3}$ & $1411^{* 4}$ & $5.8^{* 3}$ & $0.70^{* 3}$ & $0.88^{* 4}$ & $2.65^{* 3}$ & $2.6^{* 4}$ \\
\hline & SEM & 0.2 & 0.4 & 278 & 0.5 & 0.05 & 0.05 & 0.73 & 0.5 \\
\hline $\begin{array}{l}\text { normal } \\
\text { range }\end{array}$ & & $\begin{array}{l}6.8- \\
8.3\end{array}$ & $\begin{array}{l}3.8- \\
5.0\end{array}$ & $\begin{array}{l}81- \\
697\end{array}$ & $\begin{array}{l}4.5- \\
13.5\end{array}$ & $\begin{array}{l}0.99- \\
1.71^{* 6}\end{array}$ & $\begin{array}{l}0.84 \\
2.03^{* 7}\end{array}$ & $\begin{array}{l}0.42- \\
5.80\end{array}$ & $\begin{array}{l}0.11- \\
1.3^{* 8}\end{array}$ \\
\hline
\end{tabular}

*1 measured by IMX in study 1 and by Amerlex in study 2. *2 measured by equilibrium dialysis (Model FT4) in study 1 and by Coat-A-Count in study 2 . ${ }^{* 3} P<0.05$ when compared with the value before dialysis. ${ }^{* 4} P<0.01$ when compared with the value before dialysis. ${ }^{* 5}$ not done. *6 normal range for IMX. Normal range for Amerlex is $0.75-1.62 .{ }^{* 7}$ normal range for equilibrium dialysis (Model FT4). Normal range for Coat-A-Count is $0.70-2.10 .{ }^{* 8}$ normal range arbitrarily calculated with those for albumin and NEFA.

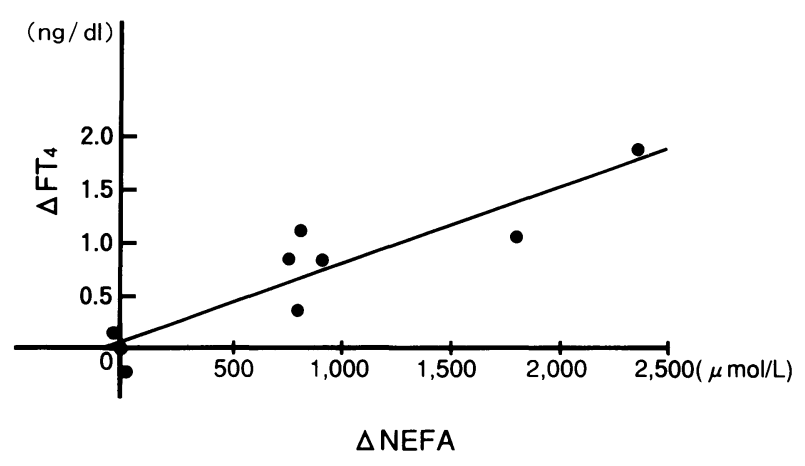

Fig. 1. Correlation between the increase in NEFA and FT4 concentrations as measured by the Model FT4 system during the first $10 \mathrm{~min}$. A significant positive correlation was observed $(r=0.916, P<0.001)$.

and did not change during the first hour, despite the increase in NEFA, but the FT4 concentration rose thereafter, and at the end of dialysis it was significantly higher than at the beginning by both methods (Table 1, lower part). The TSH concentration decreased slightly but significantly $(P<0.05)$ during hemodialysis.

The serum and plasma cortisol concentration prior to hemodialysis averaged $12.4 \pm 0.7 \mu \mathrm{g} / \mathrm{d} l$, and had not changed significantly at the end of hemodialysis $(12.1 \pm 2.2 \mu \mathrm{g} / \mathrm{d} l)$.

\section{In vitro experiments}

NEFA was measured after the overnight incubation and compared with those in the samples stored frozen. NEFA was not significantly increased by the incubation in the pre-hemodialysis serum, but NEFA was strikingly increased when plasma samples obtained $10 \mathrm{~min}$ after the start of hemodialysis were used (from $650 \pm 360$ to $1000 \pm 490 \mu \mathrm{mol} / \mathrm{L}$ ).

After sodium oleate was added at a final con- 
centration of $8 \mathrm{mmol} / \mathrm{L}$ to two normal pooled sera, the FT4 concentration was assayed by means of equilibrium dialysis (Model FT4), Coat-A-Count and the IMX kit (Fig. 2). Model FT4 measurements by equilibrium dialysis showed an increased concentration of about $60 \%$ when sodium oleate was added at a final concentration of $4 \mathrm{mmol} / \mathrm{L}$ and about a $250 \%$ increase at $8 \mathrm{mmol} / \mathrm{L}$ of sodium oleate. The FT4 concentration measured with IMX showed a $100 \%$ increase when sodium oleate was at $8 \mathrm{mmol} / \mathrm{L}$, but sodium oleate did not affect the FT4 measurements obtained with the Coat-A-Count kit (Fig. 2). The NEFA/albumin ratio was calculated to be approximately 6.4 at $4 \mathrm{mmol} / \mathrm{L}$ of sodium oleate. The TSH concentration did not show any sodium oleate-dependent change up to $8 \mathrm{mmol} / \mathrm{L}$.

\section{Discussion}

The FT4 concentration as measured by means of IMX, Amerlex and Coat-A-Count was lower in patients with chronic renal failure than in normal controls in the present study. These results are consistent with recent studies with a different assay $[16,17]$, but the FT4 concentration was normal when measured by equilibrium dialysis (Model FT4). Other investigators have reported both decreased [18] and increased [4, 14] FT4 in patients with nonthyroidal illness. A serial decrease in IMXFT4 was observed when the sample was diluted, and the value was found to be albumin dependent. Equilibrium dialysis-FT4 was not changed by the dilution of the sample. The IMX method therefore seems to cause an unduly high disturbance of the normal equilibrium that exists between $\mathrm{T} 4$ and the binding proteins. It is possibly arising from high sequestration of $\mathrm{T} 4$ from the binding proteins by the antibody especially in such circumstances as in the present study where the serum protein concentration was low. It is therefore likely that the IMX method underestimated FT4 and that the results obtained with equilibrium dialysis are correct.

FT4 measured with the Model FT4 equilibrium dialysis kit was noticeably high during hemodialysis. The FT4 concentration correlated with the NEFA and the molar ratio of NEFA/albumin. An increase in NEFA might therefore cause an increase in FT4. NEFA can be liberated by the lipolysis

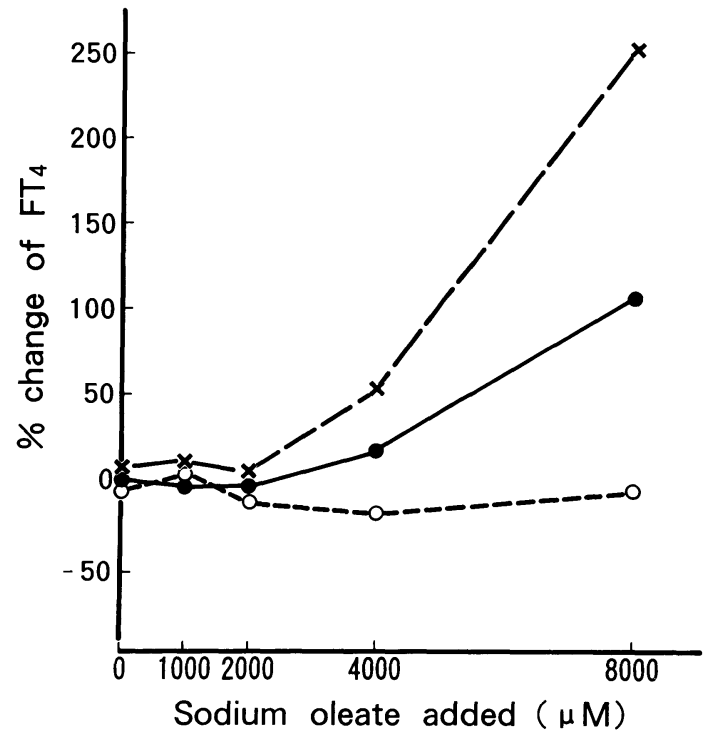

Fig. 2. In vitro effects of exogeneous sodium oleate on the FT4 concentration as determined by various assay methods ( $X$ : Model FT4 equilibrium dialysis system, $\bigcirc$ : IMX enzyme immunoassay, $\bigcirc$ : Coat-A-Count $\mathrm{T} 4$ analog method).

associated with blood collection and by equilibrium dialysis during overnight incubation [8], but FT4 measured by the three alternative methods did not show a heparin-induced increase at $10 \mathrm{~min}$ or $1 \mathrm{~h}$ after the start of dialysis.

In vitro experiments involving the addition of exogeneous sodium oleate have shown that FT4 assays based on equilibrium dialysis were sensitive to lipids and that the IMX assay also was affected but to a lesser degree. A recent study also showed a significant increase in FT4 when more than $2 \mathrm{mmol} / \mathrm{L}$ oleic acid was added to a serum sample of low albumin [11]. Although the FT4 concentration obtained by means of the Coat-ACount was unaffected by NEFA, it seemed to underestimate the NEFA-induced true in vivo increase in FT4 because of the NEFA-induced displacement of analogue tracer from albumin, making more tracer available for competition with the antibody, and leading to a spuriously low result [1].

The FT4 concentration in plasma should be constant if FT4 is removed and hemoconcentration occurs during hemodialysis [1], but we have demonstrated that FT4 increased at the end of dialysis even when measured by the Coat-A-Count, which 
may be underestimated by NEFA.

The serum TSH concentration appeared to decrease during hemodialysis. The cortisol concentration did not change significantly. It is possible that the TSH was decreased by an actual increase in FT4, although a diurnal change in TSH cannot be excluded $[19,20]$.

These data suggest that the FT4 concentration actually increased slightly during hemodialysis due to the actual increase in NEFA in vivo. The agent which increases NEFA is likely to be heparin; but furan-carboxylic acid could also be involved [21, 22]. The serum furan concentration is high in uremic patients, and would be higher at the end of hemodialysis because it is not dialysable [21]. Furan can inhibit specific $\mathrm{T} 4$ binding by increasing the free concentration of other direct competitors such as NEFA. It is therefore more likely that the FT4 concentration is increased because of the increase in NEFA caused by heparin and furan.

A high FT4 concentration could be detrimental by precipitating coronary ischemia and arrhythmias in a group of patients already predisposed to these disorders. Indeed, it has been reported that some well-compensated arrhythmias deteriorate during hemodialysis [23] and that the increased NEFA related to the incidence of arrhythmias [24]; it is speculated that FT4 changes are related to these events in high-risk patients.

To conclude, the present data indicate that: (1) The low serum FT4 in hemodialysis patients detected by some immunoassay methods is an underestimation due to the low albumin level; (2) FT4 is actually increased during hemodialysis by the actual increase in NEFA, although the marked increase in FT4 during hemodialysis as measured by equilibrium dialysis is an overestimation due to the in vitro generation of NEFA; and (3) one should beware of abberations in thyroid hormone parameters during hemodialysis and potential complications.

\section{References}

1. Ekins R (1990) Measurement of free hormones in blood. Endocr Rev 11: 5-46.

2. Hollander CS, Scott RL, Burges JA, Rabinowits D, Merimee JJ, Oppenheimer JH (1967) Free fatty acids: A possible regulation of free thyroid hormone level in man. J Clin Endocrinol Metab 27: 1219-1223.

3. Tabachnick M, Hao YL, Korcek L (1973) Effect of oleate, diphenylhydantoin, and heparin on the binding of ${ }^{125}$ I-thyroxine to purified thyroxine-binding globulin. J Clin Endocrinol Metab 36: 392-394.

4. Chopra IJ, Teco GNC, Mead JF, Huang J-S, Beredo A, Solomon DH (1985) Relationship between serum free fatty acids and thyroid hormone binding inhibitor in nonthyroidal illnesses. J Clin Endocrinol Metab 60: 980-984.

5. Liewendahl T, Helenius $H$, Naeveri $H$, Kikkanen $H$ (1992) Fatty acid-induced increase in serum dialyzable free thyroxine after physical exercise: Implication for nonthyroidal illness. J Clin Endocrinol Metab 74: 1361-1365.

6. Gotzsche LS, Weeke J (1992) Changes in plasma free thyroid hormones during cardiopulmonary bypass do not indicate triiodothyronine substitution. J Thorac Cardiovasc Surg 104: 526-527.

7. Mendel CM, Frost PH, Cavalieri RR (1986) Effect of free fatty acids on the concentration of free thyroxine in human serum: Role of albumin. J Clin Endocrinol Metab 63: 1394-1399.
8. Mendel CM, Frost PH, Kunitake T, Cavalieri RR (1987) Mechanism of the heparin-induced increase of free thyroxine in plasma. J Clin Endocrinol Metab 65: 1259-1264.

9. Chan MK, Varghese Z, Moorhead JF (1981) Lipid metabolism in uremia, dialysis and transplantation (Editorial review). Kidney Internat 19: 625-637.

10. Hershman JM, Jones CM, Bailey AL (1972) Reciprocal in serum thyrotropin and free thyroxine produced by heparin. J Clin Endocrinol Metab 34: 574-579.

11. Christofides ND, Sheehan CP (1995) Enhanced chemiluminescence labeled-antibody immunoassay (Amerlite-MAB) for free thyroxine: Design, development, and technical validation. Clin Chem 41: 17-23.

12. Nishikawa $M$, Mashio $Y$, Tanaka $K$, Ishii $K$, Naito K, Inada M, Imura H, Usami K, Kurobe T, Nakajima $\mathrm{K}$ (1982) The influence of fatty acids on thyroxine and 3,3'-diiodothyronine levels in patients with chronic renal failure on hemodialysis. Folia Endocrinol Japon 58: 122-130 (In Japanese).

13. Csako G, Zweig MH, Glickman J, Kestner J, Ruddel M (1989) Direct and indirect techniques for free thyroxin compared in patients with nonthyroidal illness. I. Effect of free fatty acids. Clin Chem 35: 102-109.

14. Docter $R$, Toor $H$, Krenning EP, Jong $M$, 
Hennemann G (1993) Free thyroxine assessed with assays in sera of patients with nonthyroidal illness and of subjects with abnormal concentrations of thyroxine-binding proteins. Clin Chem 39: 16681674.

15. Witherspoon LR, El Shami AS, Shuler SE, Neely H, Sonnemaker R, Gilbert SS, Alyea K (1988) Chemically blocked analog assay for free thyronines. Clin Chem 34: 9-16, 17-23.

16. Sheehan CP, Christofides ND (1992) One-step, labeled-antibody assay for measuring free thyroxine. II. Performance in a multicenter trial. Clin Chem 38: 19-25.

17. Midgley JEM, Sheehan CP, Christofides ND, Fry JE, Browing D, Mardell R (1990) Concentration of free thyroxine and albumin in serum in severe nonthyroidal illness: Assay artifacts and physiological influences. Clin Chem 36: 765-771.

18. Liewendahl $K$, Tikanoja $S$, Maehoenen $H$, Helenius T, Vaelimaeki M, Tallgren LG (1987) Concentration of iodothyronines in serum of patients with chronic renal failure and other nonthyroidal illnesses: Role of free fatty acids. Clin Chem 33: 1382-1386.

19. Scanlon MF, Toft AD (1996) Thyrotropin. In: Braverman LE, Utiger RD (eds) Werner and Ingbar's
The Thyroid. 7th ed, Lippincott-Raven, Philadelphia, 226.

20. Caron PJ, Nieman LK, Rose SR, Nisula BC (1986) Deficient nocturnal surge of thyrotropin in central hypothyroidism. J Clin Endocrinol Metab 62: 960964.

21. Henderson SJ, Lindup WE (1992) Renal organic acid transport: Uptake by rat kidney slices of a furan dicarboxylic acid which inhibits plasma protein binding of acid ligands in uremia. J Pharmacol Exp Therap 263: 54-60.

22. Lim C, Stockigt JR,Curtis AJ, Wynne KN, Barlow JW, Topliss DJ (1993) A naturally occurring furan fatty acid enhances drug inhibition of thyroxine binding in serum. Metabolism 42: 1468-1474.

23. Kimura K, Tabei K, Asano J, Hosoda S (1989) Cardiac arrhythmias in hemodialysis patients. A study of incidence and contributory factors. Nephron 53: 201-207.

24. Arnessen H, Skjaeggestad O, Wik B (1980) Plasma free fatty acids and the incidence of arrhythmia in acute myocardial infarction during treatment with small doses of subcutaneous heparin or warfarin. Acta Med Scand 49: 606-612. 